\title{
EXPERIMENTAL INVESTIGATION AND ANALYSIS OF
}

\section{SMAW PROCESSED CARBON STEEL PIPES}

\section{RAJIV SELVAM \& SURJITH JACOB}

Manipal Academy of Higher Education, School of Engineering \& IT, Dubai, United Arab Emirates

Pipelines all over the world carry a huge quantity of oil, gas and petroleum products. If there is any leakage or burst occurs in these pipelines, it will affect our environment drastically resulting in loss of life, time and economy. The various causes for the pipelines to fail, mainly internal weld discontinuities such as lack of penetration, lack of fusion, slag inclusions, cracks etc. have been identified. Over the years, several studies were conducted in pipeline welding field to get less defective or defect-free weld joints by resorting to various welding techniques such as Shielded Metal Arc Welding (SMAW), Gas Metal Arc Welding (GMAW/MIG) etc. Selection of the type of weld mainly depends on the application in which it will be used and the working pressure of the fluid. The study focuses on the quality of weld in the centralized Liquefied Petroleum Gas (LPG) piping system found in the residential and commercial buildings in U. A. E. Shielded Metal Arc Welding (SMAW) technique is selected for the work and an attempt has been made to get the best quality weld by using different combinations of weld electrodes. In this present work, the experimental investigation and analysis of SMAW processed carbon steel pipes were discussed. Two different combinations of electrode materials were used for this investigation. The main objective of this work is to suggest the best combination of weld electrode material for the centralized Liquefied Petroleum Gas piping system.
\end{abstract}

KEYWORDS: SMAW, Weld Defects, Electrodes \& Vicker Hardness

Received: Jul 11, 2018; Accepted: Aug 01, 2018; Published: Aug 22, 2018; Paper Id.: IJMPERDOCT20185

\section{INTRODUCTION}

The shielded metal arc welding (SMAW) is one of the simplest and most versatile arc welding processes in which an electric arc between a covered metal electrode and the workpiece generates the heat for welding. The filler metal is deposited from the electrode, and the electrode covering provides the shielding. it can be used to weld both ferrous and non-ferrous metals [1]. The arc is under the control of the welder and is visible. The welding process leaves slag on the surface of the weld bead which must be removed. The most common use for this process is welding mild and low alloy steels. The equipment is extremely rugged and simple, and the process is flexible in that the welder needs to take only the electrode holder and work lead to the point of welding [2]. The welding circuit includes a power source, welding cables, an electrode holder, a work clamp and a welding electrode. One of the welding cables connects the power source to the electrode holder and the other cable connects to the workpiece Welding. The begins when the welder initiates the arc by momentarily touching the electrode to the base metal, which completes the electric circuit. The welder guides the electrode manually, controlling both the travel speed and the direction of travel. The welder maintains the arc by controlling the distance between the work material and the tip of the electrode (length of the arc) [3]. Shielded Metal arc welding is particularly dominant in the maintenance and repair industry and is heavily used in the construction of steel structures and in industrial 
fabrication. SMAW is often used to weld carbon steel, low and high alloy steel, stainless steel, cast iron and ductile iron. While less popular for non-ferrous materials, it can be used on nickel and copper and their alloys and, in rare cases, on aluminum [7]. Two different combinations of electrodes were selected for the study and two carbon steel pipe weld specimens were prepared out of it. Vickers hardness test, tensile test, and Radiographic examination were conducted on the weld specimens. The Vickers hardness value, stress-strain relationship, and weld defects were identified in the experiment. The experimental data were compared for each weld specimens. With these observations, a few practical issues in selecting the electrode combinations for multi-pass welding of carbon steel pipes were addressed. The traditional way of welding a carbon steel pipe is using a fast fill electrode (E7010) for the root pass followed by low hydrogen electrode (E7018) for the final weld run. In the present study, it was observed that selecting a fast freeze electrode (E6010) for the root pass followed by a low hydrogen electrode (E7018) for the final weld run would reduce the weld defects and increase the quality of the weld. The results revealed that the Vickers hardness and stress-strain values for both the specimens are almost the same but there is a significant difference in the weld defects observed. In this article, the power source used for welding is a portable and lightweight Minarc Kemppi 150 model welding machine. Vickers hardness equipment was used to measure hardness values and a universal testing machine was used to carry out the tensile test. The study offers valuable information about the different weld defects associated with SMAW.

\section{EXPERIMENTAL PROCEDURE}

A Carbon steel pipe (A106 Gr. B Sch.40) of thickness 4 inches is selected as the specimen to conduct the experiments. The specimen is oriented in $6 \mathrm{G}$ welding position to proceed with the welding. The schematic diagram illustrating the experimental set-up is shown in Figure 1. The experiments were conducted on two weld specimens to evaluate and compare hardness values, stress-strain values, and weld defects.

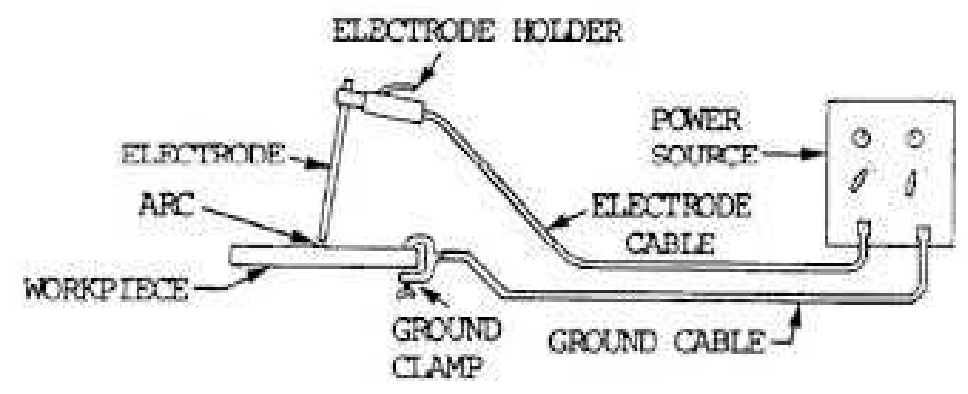

Figure 1: Equipment Set Up of SMAW

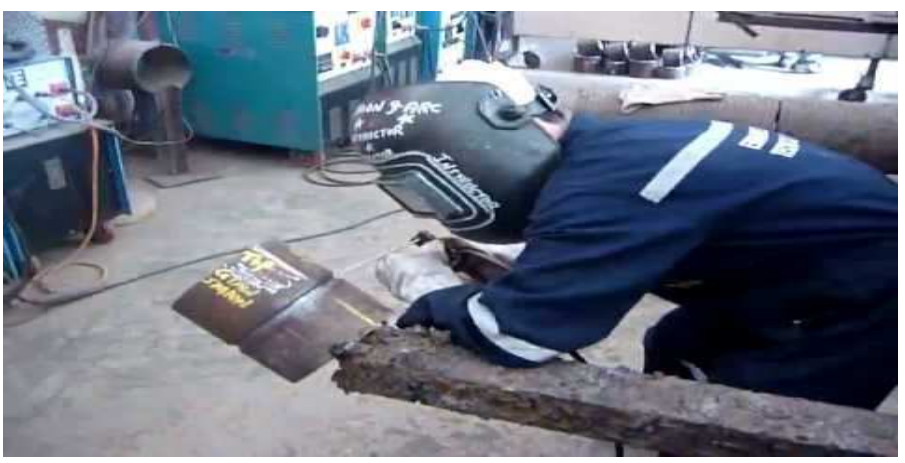

Figure 2: Photograph of 6G Weld Position Adopted for Preparing Weld Specimen for the Study 
Figure 2 shows the photograph of the 6G Weld position adopted for preparing weld specimen for the study. Although the SMAW process has relatively basic equipment requirements, it is important that the welder has knowledge of operating features and performance to comply with welding procedures for the job and of course for safety reasons. The main components required for welding are the power source, electrode holder and cables, welder protection and fume extraction. The required tools include a wire brush to clean the joint area adjacent to the weld; a chipping hammer to remove slag from the weld deposit; and, when removing slag, a pair of clear lens goggles or face shields to protect the eyes.

\section{EXPERIMENTAL SET-UP}

\section{Power Source}

The purpose of the power source is to provide the electric power of the proper current and voltage to maintain a welding arc. Many different sizes and types of power sources are designed for shielded metal arc welding. SMAW electrodes are designed to be operated with alternating current (AC) and direct current (DC) power sources. As MMA requires a high current (50-300A) but a relatively low voltage (10-50V), high voltage main supplies ( 240 or $440 \mathrm{~V})$ must be reduced by a transformer. Figure 3 shows the portable and lightweight welding machine used for preparing the weld specimens.

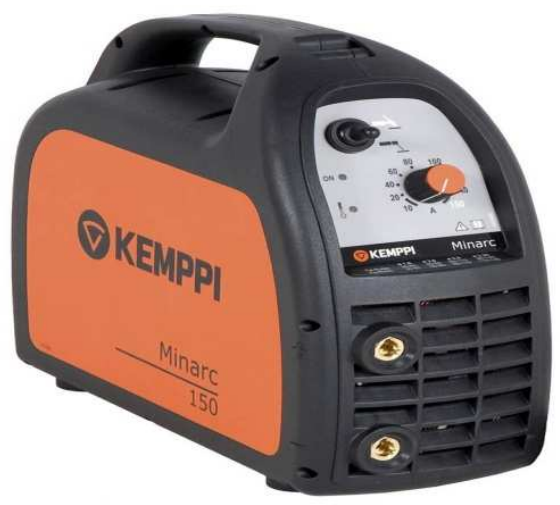

Figure 3: Welding Machine

\section{Electrode Holder and Cables}

An electrode holder, commonly called a stinger, is a clamping device for holding the electrode surely in any position as shown in Figure 4. The welding cable attaches to the holder through the hollow insulated handle. The design of the electrode holder permits quick and easy electrode exchange. Two general types of electrode holders are in use: insulated and non- insulated. Each holder is designed for use within a specified range of electrode diameters and welding current. Welding with a machine having a 300-ampere rating requires a larger holder than welding with a 100-ampere machine. If the holder is too small, it will overheat.

The welding cables and connectors connect the power source to the electrode holder and to the work. These cables are normally made of copper or aluminum. The cable that connects the work to the power source is called the work lead. The cable that connects the electrode holder to the power source is called the electrode lead. The welding cables must be flexible, durable, well insulated, and large enough to carry the required current. Two factors determine the size of the welding cable to use: the amperage rating of the machine and the distance between the work and the machine [3]. 


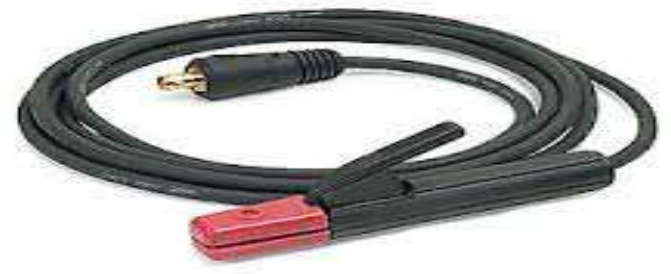

Figure 4: Electrode Holder and Cables

\section{Materials}

Two Carbon steel pipes of 4" diameter and length of $300 \mathrm{~mm}$ each were cut into two halves i.e at a sample length of $150 \mathrm{~mm}$ each. The sample pieces were joined by SMAW process to prepare the weld specimens for the study. The chemical composition of carbon steel pipe in terms of weight was found to be $0.30 \% \mathrm{C}, 0.29 \% \mathrm{Mn}, 0.03 \% \mathrm{P}$ and $\mathrm{S}$ each, $0.10 \% \mathrm{Si}, 0.40 \% \mathrm{Cr}, \mathrm{Ni}$ and $\mathrm{Cu}$ each, $0.15 \% \mathrm{Mo}$ and $0.08 \% \mathrm{~V}$. The photograph of carbon steel pipe beveled at one end prior to welding is shown in Figure 5 and the photograph of SMAW processed carbon steel pipe are shown in Figure 6.

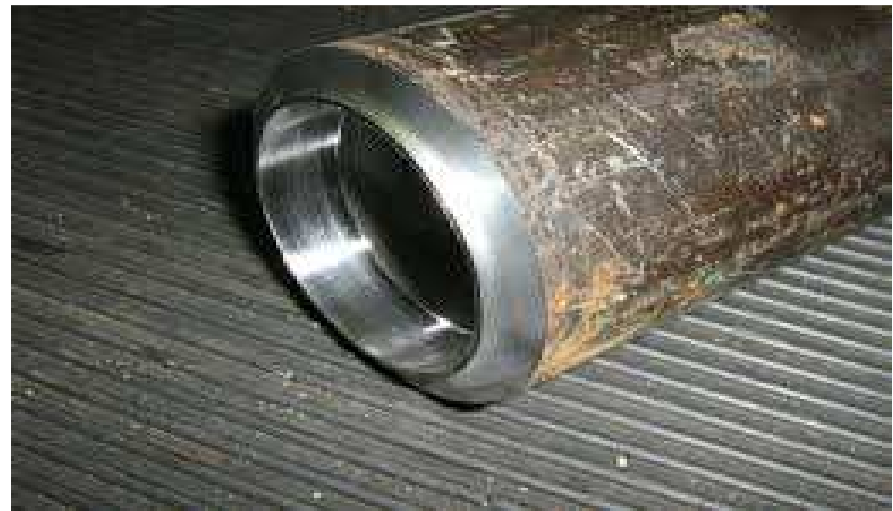

Figure 5: Photograph of Carbon Steel Pipe Beveled at One End Prior to Welding

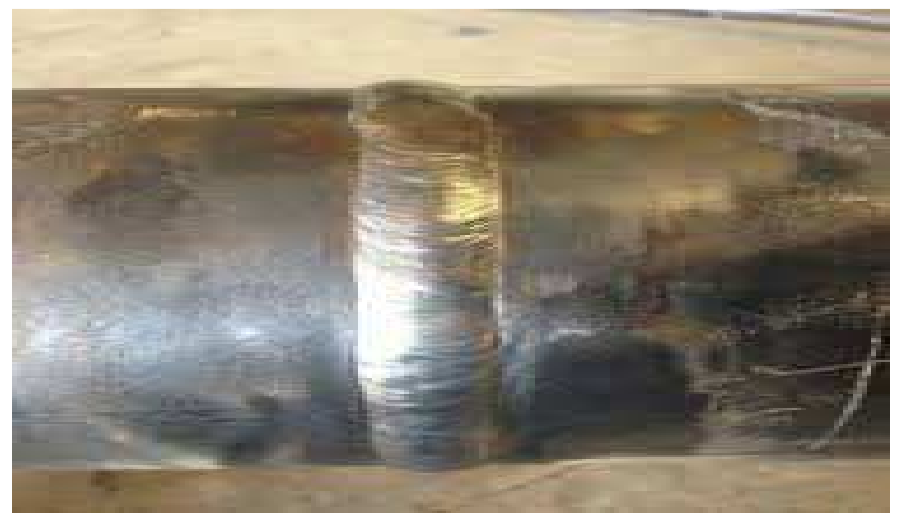

Figure 6: Photograph of SMAW Processed Carbon Steel Pipe 


\section{RESULTS AND DISCUSSIONS}

\section{Comparative Study of Vickers Hardness Values}

Vickers Hardness test was carried out on two welded carbon steel (A106 Gr. B Sch.40) seamless pipes of 4-inch diameter and $300 \mathrm{~mm}$ length. Vickers hardness equipment was used to measure the hardness values of each specimen. The indentations are provided on the base metal, weld area, and the heat affected zone. The areas for each indentation are categorized into A, B, C, D, E, F, G, H, I and J. Figure 7 shows the line diagram of weld specimen considered for Vickers Hardness test. Three indentations are made on each area as shown in Figure 8 below and their corresponding hardness values are calculated and recorded as shown in table 1 .

The Vickers hardness is the quotient obtained by dividing the KGF load by the square mm area of indentation.

$$
\begin{aligned}
& \mathrm{VHN}=[2 \mathrm{P} \sin (136 / 2)] / \mathrm{d}^{\wedge} 2 \\
& \mathrm{P}=\text { load (it can be varied from } 1 \text { to } 1000 \text { grams). } \\
& \mathrm{d}=\text { average diagonal diameter of indentation }[\mathrm{mm}]
\end{aligned}
$$

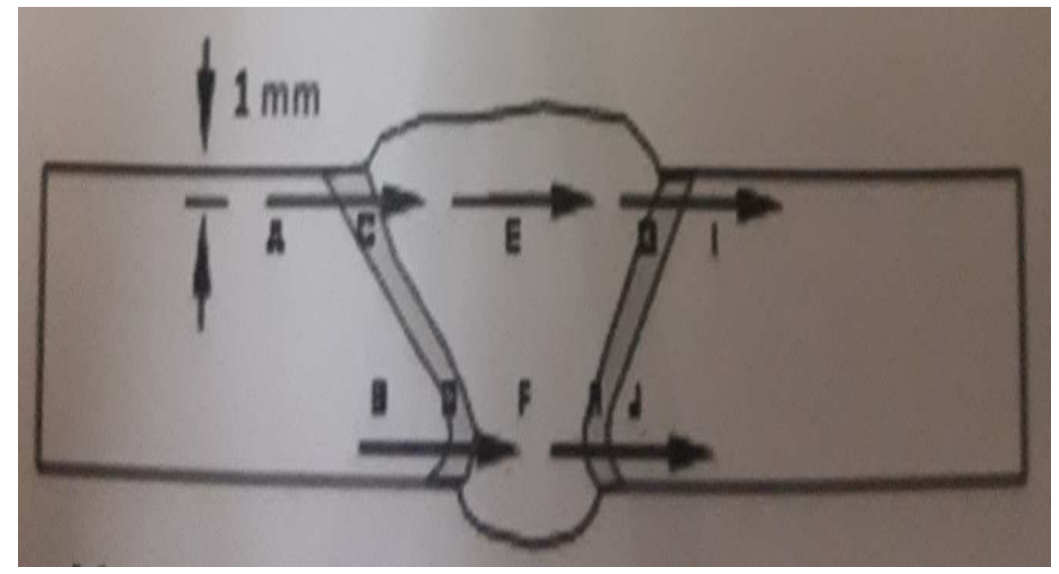

Figure 7: Photograph of Line Diagram of Weld Specimen Taken for Vickers Hardness Test

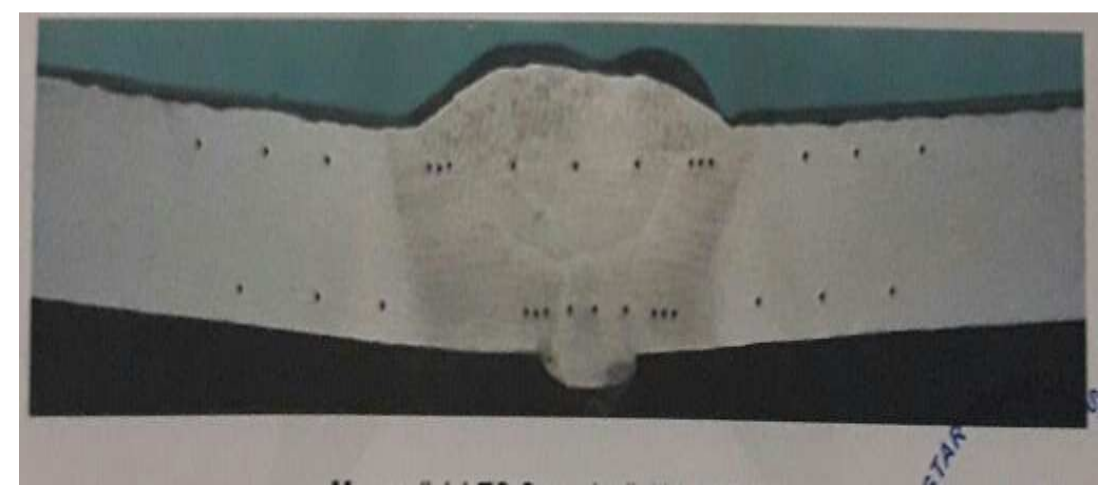

Figure 8: Photograph of Indentations Done On Parent Metal, Weld Area and HAZ of Weld Specimen

From the below table 1, it is observed that the maximum hardness value is 195 which is found in the heat affected zone. 
Table 1: Hardness Values for Welded Specimen 1

\begin{tabular}{|c|c|c|c|c|c|c|c|c|c|}
\hline A & B & C & D & E & F & G & H & I & J \\
\hline \multicolumn{2}{|c|}{ PM } & \multicolumn{2}{|c|}{ HAZ } & \multicolumn{2}{c|}{ WELD } & \multicolumn{2}{|c|}{ HAZ } & \multicolumn{2}{|c|}{ PM } \\
\hline 160 & 162 & 190 & 186 & 183 & 184 & 193 & 187 & 164 & 165 \\
\hline 157 & 161 & 192 & 188 & 185 & 188 & 189 & 185 & 162 & 166 \\
\hline 158 & 160 & $\underline{195}$ & 190 & 186 & 186 & 191 & 184 & 163 & 165 \\
\hline
\end{tabular}

The same procedure has been followed for the welded specimen 2 and the results are recorded as shown in the below table 2 .

Table 2: Hardness Values for Welded Specimen 2

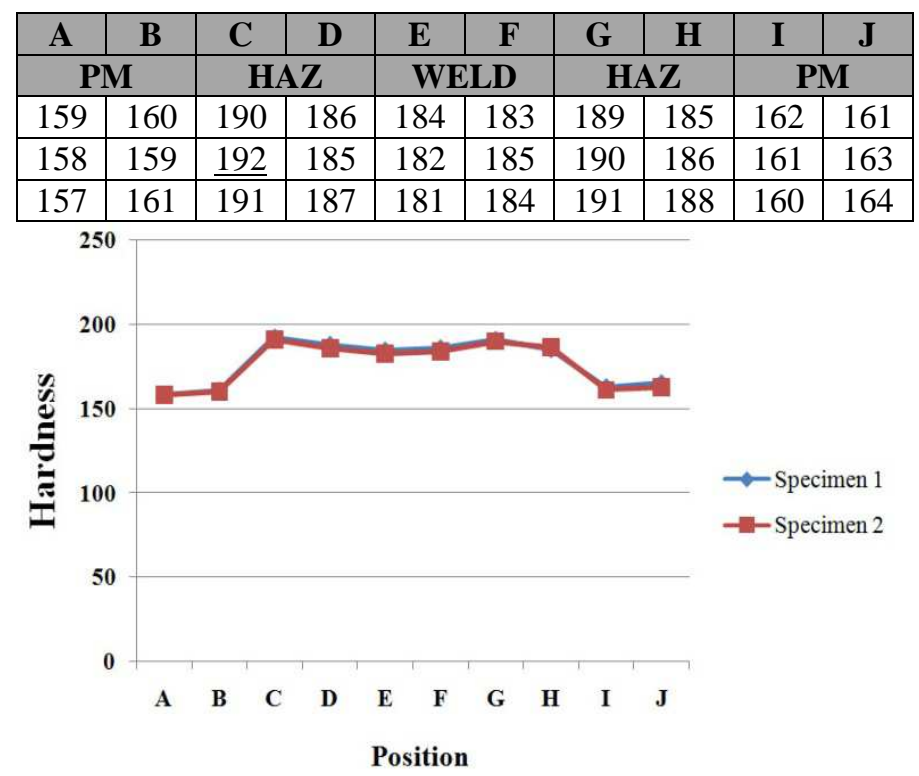

Figure 9: Correlation of Variations in Hardness at Different Positions of Welded Specimen 1 and 2

The above figure 9 represents the correlation of variations in hardness at different positions of welded specimen 1 and 2. Position A \& B, I \& J are in the parent metal. Position C \&D, G\&H are in the heat affected zone, Position E\&F are in the weld area. The hardness values in the heat affected zones are much higher than the parent metal and weld area. The main reason is that the cooling rate at heat affected zone welded specimen is very higher than at the parent metal and weld area and the microhardness function is directly proportional to cooling at that point. Higher the cooling rate will produce higher microhardness.

Tensile Test AnalysisA tensile test is carried out in terms of the present study is to compare and contrast the tensile strengths of welded specimen 1 and welded specimen 2 and also to study their stress-strain relationships as shown in Figure 10. 


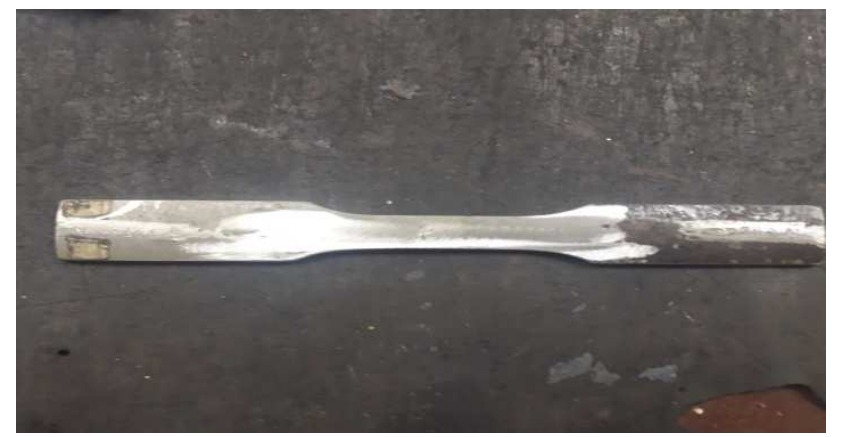

Figure 10: Tensile Test Specimen

The below table 3 and table 4 shows the dimensional details of welded specimen 1 and 2 and the results of tensile test specimen $1 \& 2$ presented in table 5 and 6.

Table 3: Dimensional Details ofWeld Specimen

\begin{tabular}{|c|c|}
\hline Size, $\mathrm{mm}$ & $18.90 \times 5.35$ \\
\hline Area, $\mathrm{mm}^{\wedge} 2$ & 101.11 \\
\hline
\end{tabular}

Table 4: Dimensional Details of Weld Specimen 2

\begin{tabular}{|c|c|}
\hline Size, $\mathrm{mm}$ & $18.90 \times 5.35$ \\
\hline Area, $\mathrm{mm}^{\wedge} 2$ & 101.11 \\
\hline
\end{tabular}

Table 5: Results of Tensile Test Specimen 1

\begin{tabular}{|c|c|c|c|c|}
\hline Time & $\begin{array}{c}\text { Extension } \\
\text { (in mm) }\end{array}$ & $\begin{array}{c}\text { Load } \\
(\mathbf{N})\end{array}$ & $\begin{array}{c}\text { Stress } \\
\text { (MPa) }\end{array}$ & $\begin{array}{c}\text { Strain } \\
(\mathbf{m m})\end{array}$ \\
\hline 0 & 0 & 0.90 & 0.05 & 0 \\
\hline 10 & 0.83 & 4694.34 & 238.89 & 0.010 \\
\hline 20 & 1.67 & 4831.41 & 245.87 & 0.021 \\
\hline 30 & 2.50 & 4781.08 & 243.30 & 0.031 \\
\hline 40 & 3.33 & 4918.83 & 250.31 & 0.042 \\
\hline 50 & 4.17 & 4926.58 & 250.71 & 0.052 \\
\hline 60 & 5.00 & 5257.07 & 267.53 & 0.062 \\
\hline 70 & 5.83 & 5437.01 & 276.68 & 0.073 \\
\hline 80 & 6.66 & 5575.88 & 283.75 & 0.083 \\
\hline 81 & 6.75 & 5584.21 & 284.18 & 0.084 \\
\hline 81.1 & 6.76 & 5584.04 & 284.17 & 0.084 \\
\hline 81.2 & 6.77 & 5591.60 & 284.55 & 0.085 \\
\hline 81.3 & 6.77 & 5587.98 & 284.37 & 0.085 \\
\hline 100 & 8.33 & 5775.18 & 293.89 & 0.104 \\
\hline 110 & 9.16 & 5847.52 & 297.57 & 0.115 \\
\hline 120 & 10.00 & 5911.04 & 300.81 & 0.125 \\
\hline 130 & 10.83 & 5965.41 & 303.57 & 0.135 \\
\hline 140 & 11.67 & 6010.53 & 305.87 & 0.146 \\
\hline 150 & 12.50 & 6042.57 & 307.50 & 0.156 \\
\hline 160 & 13.33 & 6072.26 & 309.01 & 0.167 \\
\hline 170 & 14.16 & 6092.93 & 310.06 & 0.177 \\
\hline 180 & 15.00 & 6113.24 & 311.10 & 0.187 \\
\hline 190 & 15.83 & 6129.65 & 311.93 & 0.198 \\
\hline 200 & 16.67 & 6140.36 & 312.48 & 0.208 \\
\hline 210 & 17.50 & 6146.37 & 312.78 & 0.219 \\
\hline 220 & 18.33 & 6148.14 & 312.87 & 0.229 \\
\hline 230 & 19.16 & 6149.17 & 312.93 & 0.240 \\
\hline 240 & 20.00 & 6147.15 & 312.82 & 0.250 \\
\hline 250 & 20.83 & 6142.22 & 312.57 & 0.260 \\
\hline & & & & \\
\hline
\end{tabular}




\begin{tabular}{|c|c|c|c|c|}
\hline 260 & 21.66 & 6130.59 & 311.98 & 0.271 \\
\hline 270 & 22.50 & 6120.44 & 311.46 & 0.281 \\
\hline 280 & 23.33 & 6099.74 & 310.41 & 0.292 \\
\hline 290 & 24.16 & 6050.83 & 307.92 & 0.302 \\
\hline 300 & 25.00 & 5940.21 & 302.29 & 0.312 \\
\hline 310 & 25.83 & 5675.33 & 288.81 & 0.323 \\
\hline 320 & 26.67 & 4725.52 & 240.48 & 0.333 \\
\hline 322.2 & 26.84 & 358.03 & 18.22 & 0.336 \\
\hline 322.2 & 26.85 & 79.03 & 4.02 & 0.336 \\
\hline 322.2 & 26.85 & -7.95 & -0.40 & 0.336 \\
\hline
\end{tabular}

Table 6: Results of Tensile Test Specimen 2

\begin{tabular}{|c|c|c|c|c|}
\hline Time & $\begin{array}{c}\text { Extension } \\
\text { (in } \mathbf{m m} \text { ) }\end{array}$ & $\begin{array}{c}\text { Load } \\
(\mathbf{N})\end{array}$ & $\begin{array}{c}\text { Stress } \\
\text { (MPa) }\end{array}$ & $\begin{array}{c}\text { Strain } \\
(\mathbf{m m})\end{array}$ \\
\hline 0 & 0 & 0.811 & 0.024 & 0 \\
\hline 10 & 0.832 & 4521.62 & 231.40 & 0.010 \\
\hline 20 & 1.665 & 4731.22 & 237.65 & 0.021 \\
\hline 30 & 2.498 & 4788.34 & 234.21 & 0.031 \\
\hline 40 & 3.332 & 4822.14 & 241.87 & 0.042 \\
\hline 50 & 4.165 & 4836.62 & 241.43 & 0.052 \\
\hline 60 & 4.998 & 5157.07 & 260.11 & 0.062 \\
\hline 70 & 5.832 & 5347.26 & 268.49 & 0.073 \\
\hline 80 & 6.665 & 5565.88 & 275.21 & 0.083 \\
\hline 81 & 6.748 & 5572.39 & 276.38 & 0.084 \\
\hline 81.1 & 6.757 & 5573.10 & 276.88 & 0.084 \\
\hline 81.2 & 6.765 & 5580.65 & 276.94 & 0.085 \\
\hline 81.3 & 6.772 & 5587.21 & 276.80 & 0.085 \\
\hline 100 & 8.332 & 5765.69 & 284.46 & 0.104 \\
\hline 110 & 9.162 & 5850.83 & 288.57 & 0.115 \\
\hline 120 & 10.022 & 5901.28 & 295.11 & 0.125 \\
\hline 130 & 10.834 & 5955.41 & 300.39 & 0.135 \\
\hline 140 & 11.672 & 6005.47 & 303.64 & 0.146 \\
\hline 150 & 12.514 & 6035.57 & 305.87 & 0.156 \\
\hline 160 & 13.331 & 6061.31 & 307.00 & 0.167 \\
\hline 170 & 14.163 & 6085.29 & 309.18 & 0.177 \\
\hline 180 & 15.011 & 6105.64 & 310.22 & 0.187 \\
\hline 190 & 15.833 & 6125.22 & 310.54 & 0.198 \\
\hline 200 & 16.672 & 6140.19 & 311.39 & 0.208 \\
\hline 210 & 17.543 & 6142.35 & 311.46 & 0.219 \\
\hline 220 & 18.333 & 6145.11 & 311.76 & 0.229 \\
\hline 230 & 19.164 & 6147.81 & 311.88 & 0.240 \\
\hline 240 & 20.013 & 6144.42 & 311.96 & 0.250 \\
\hline 250 & 20.834 & 6141.68 & 310.42 & 0.260 \\
\hline 260 & 21.665 & 6129.47 & 309.32 & 0.271 \\
\hline 270 & 22.504 & 6119.36 & 309.39 & 0.281 \\
\hline 280 & 23.334 & 6098.21 & 308.00 & 0.292 \\
\hline 290 & 24.165 & 6051.39 & 306.11 & 0.302 \\
\hline 300 & 25.001 & 5938.74 & 301.44 & 0.312 \\
\hline 310 & 25.834 & 5670.93 & 285.68 & 0.323 \\
\hline 320 & 26.672 & 4721.73 & 235.19 & 0.333 \\
\hline 322.2 & 26.843 & 350.04 & 16.34 & 0.336 \\
\hline 322.2 & 26.851 & 75.83 & 3.02 & 0.336 \\
\hline 322.2 & 26.851 & -6.80 & -0.26 & 0.336 \\
\hline & & & & \\
\hline
\end{tabular}




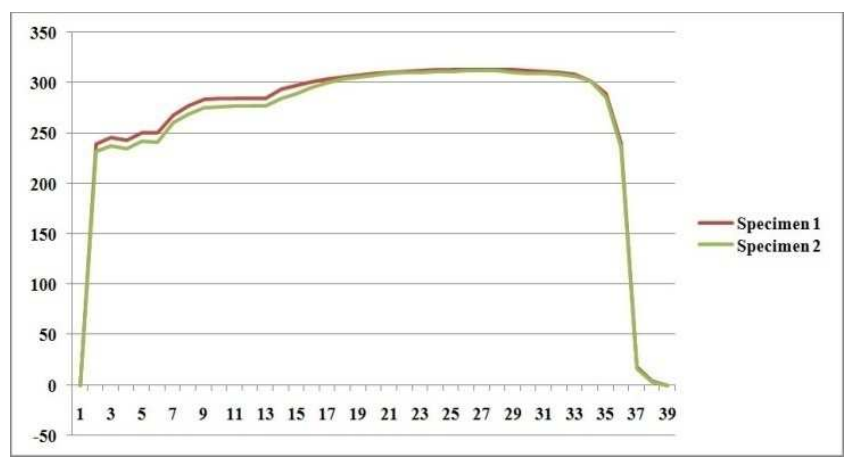

Figure 11: Comparison of Stress Vs Strain for Specimen 1 and Specimen 2

The data obtained from the universal testing machine shows the difference in rates of extensions in both the specimens is plotted in Figure 11. Specimen 1 reached yield point at the stress of $240 \mathrm{MPa}$ while Specimen 2 reached yield strength of $231 \mathrm{MPa}$. Hence it can be seen that specimen 1 has high tensile strength compared to Specimen 2. When subjected to the same amount of load, there was a relatively high extension in specimen 2 than in specimen 1 . This can be attributed to the difference in microcrystalline structures of the two specimens. The specimen 1 have a higher gradient than specimen 2. The gradients of stress-strain curves give the Young's Modulus, which affect the deflection of material under different loads. Further loading of both specimens beyond the yield point gave a stack difference. The specimen 1 reached fracture point of approximately $335 \mathrm{MPa}$ while specimen 2 reached fracture at $300 \mathrm{MPa}$. Changes in length indicate the ductility of the material when loaded. In the graph, it can be seen that for engineering stressstrain curves, the curves drop downwards after necking has occurred. However, this phenomenon cannot be seen in normal true stress-strain curves, the curves would reach the highest region of fracture.

Radiographic Defect Analysis

Table 7: Radiographic Weld Defects Observed for Weld Specimen 1 and 2

\begin{tabular}{|l|c|c|}
\hline \multicolumn{1}{|c|}{ Defect Name } & Weld Specimen 1 & Weld Specimen 2 \\
\hline Lack of sidewall fusion & Nil & Nil \\
\hline Lack of penetration & Nil & Present \\
\hline Burn through & Nil & Present \\
\hline Porosity & Nil & Nil \\
\hline Crater & Nil & Nil \\
\hline Crater cracking & Nil & Present \\
\hline Spatter & Slightly occur & Present \\
\hline Under flushing & Nil & Present \\
\hline Solidification cracking & Nil & Present \\
\hline Incomplete fill concavity & Nil & Present \\
\hline
\end{tabular}

From the above table 7 radiographic defect analysis, it can be concluded that sample 1 (combination of electrode E6010 \& E7018) has shown no weld defects when compared to sample 2 (combination of electrode E7010 \& E7018). The defects which are been checked for has been listed in the above table. The combination of electrode E6010 \& E7018 offer low spatter levels and a smooth, stable and quiet arc. These filler metal characteristics give the welding operator good control over the arc and minimize the post weld clean up- both important factors in applications that require careful attention to weld quality and heat input and those on strict deadlines. Moreover, they offer good deposition rates and good penetration, which means welding operators can add more weld metal into the joint in a given time. Good arc starts and 
restarts, which help eliminate issues like porosity at the start of the weld, are the additional benefits of electrode E6010 \& E7018.

\section{CONCLUSIONS}

In the multi-pass welding process parameters directly affect the number of passes and total heat input. The individual effect of current, voltage, speed on hardness of weld and heat affected zone is higher. It is observed that the hardness is higher in the heat affected zone than the weld metal. With increasing cooling rate, hardness increases in the weld metal and heat affected zone at the higher cooling rate. Based upon the present study, it is recommended that for the multi-pass welding of carbon steel pipes using SMAW process, electrode combination E6010 \& E7018 are preferred over E7010 \& E7018 because of the reason that it gives good hardness, toughness, and ductility to the material.

Many engineering applications that require high tensile strength normally use mild steel or carbon steel. This is because of their crystalline structure that allows it to withstand high axial loads before fracture can occur. Based on the present study, both the weld specimen base material is carbon steel and it was observed that the tensile strength of specimen 1 is slightly higher than specimen 2. Therefore, it is always recommended to select an electrode combination of E6010\&E7018 to carry out welding of carbon steel pipes.

From the radiography examination, it has been observed that the combination of electrode E6010 \& E7018 offer low spatters levels and a smooth, stable and quiet arc. These filler metal characteristics give the welding operator good control over the arc and minimize the post weld clean up- both important factors in applications that require careful attention to weld quality and heat input and those on strict deadlines. Moreover, they offer good deposition rates and good penetration, which means welding operators can add more weld metal into the joint in a given time.

The scope for future research in this topic is to carry out multi-pass welding in carbon steel pipes by trying a different combination of electrode consumables that will give better and defect-free weld joints. Moreover, the electrode combinations are to be selected in such a way that it should give less amount of slag in order to avoid grinding to get the better surface finish. Since SMAW is a manual welding process, this will be helpful for the welder to save time and the process remains inexpensive.

\section{REFERENCES}

1. Vijayesh Rathi, Hunny 'Analyzing the effect of parameters on SMAW processes. International journal of emerging research in management and technology. ISSN: 2278-9359, Volume 4, Issue 6, June 2015.

2. Prakash $M$, Robert Henry. 'An experimental investigation of weld defects in shielded metal arc welding'. International journal of research in engineering, science and technologies ISSN:2454-5392, Volume 1, Issue 8, April 2016.

3. Gurpreet Singh Sidhu, Sukhpal Singh Chatha 'Role of shielded metal arc welding consumables on pipe weld joint' International Journal of Emerging technology and Advanced Engineering, Volume 2, Issue 12, 2012.

4. G. Magudeeswaran, V. Balasubramanian, G. Madhusudhan Reddy 'Effect of welding processes and consumables on tensile and impact properties of high strength quenched and tempered steel joints' Journal of iron and steel research international, August 19, 2007, Pages 87-94.

5. Shinde R. S, Galhe D. S, 'Experimental Investigation for strength of steel using arc welding'. International journal of pressure vessels and piping, Volume 84, Issue 5, May 2007, Pages 298-303. 
6. Jun Yan, Ming Gao, Xiaoyan Zeng. ' Study on microstructure and mechanical properties of 304 stainless steel joints by TIG, Laser and Laser-TIG hybrid welding'. Optics and lasers in engineering, Volume 48, Issue 4, April 2010, Pages 512-517.

7. S. Murugan, P. V. Kumar, B. Raj, M. S. C. Bose. 'Temperature distribution during multi-pass welding of plates'. International journal of pressure vessels and piping, Volume 75, Issue 12, October 1998, Pages 891-905.

8. Olafimihan, E., Oyetunji, O., \& Oladapo, M. Failure Analysis Of The Flowline Of Crude Oil In Pipes.

9. Rajiv S, Shanmuga Sundaram, K, Pablo Pasquale.: Experimental Investigation and Finite Element Analysis on Electromagnetic Compression Forming Processed Aluminum Alloy Tubes. Applied Mechanics and Materials 110-116 (2012)

10. S. Murugan, Sanjai, K. Rai, P. V. Kumar 'Temperature distribution and residual stresses due to multi-pass welding in type 304 stainless steel and low carbon steel weld pads' International journal of pressure vessels and piping, Volume 78, Issue 4, April 2001, Pages 307-317.

11. Subodh Kumar, A. S. Shahi. "Effect of heat input on the microstructure and mechanical properties of gas tungsten arc welded AISI 304 stainless steel joints' Materials and Design, Volume 32, Accepted 7th February 2011, Pages 3617-3623. 
